\title{
The higher air temperature was closely associated with higher ambulance transports due to heat stroke in elderly Japanese
}

\author{
Nobuyuki Miyatake*, Noriko Sakano, Shoko Murakami \\ Department of Hygiene, Faculty of Medicine, Kagawa University, Miki, Japan. \\ Email: ${ }^{*}$ miyarin@med.kagawa-u.ac.jp
}

Received 7 October 2011; revised 12 November 2011; accepted 20 November 2011.

\begin{abstract}
To investigate the link between higher air temperature and ambulance transports due to heat stroke, especially in elderly subjects, using daily data in Saitama prefecture in August, 2010, Japan. We obtained daily data of air temperature in Saitama prefecture in August, 2010, Japan from Japan Meteorological Agency. Number of ambulance transports due to heat stroke was also used by Saitama prefecture official website. The effect of high air temperature on ambulance transports due to heat stroke was evaluated. A total of 1688 ambulance transports due to heat stroke was observed in Saitama prefecture in August, 2010, Japan. Seven hundred and twenty one subjects $(42.7 \%)$ were over the age of 65 . Mean air temperature, the highest air temperature and day light hours were significantly associated with ambulance transports due to heat stroke in total subjects (mean air temperature: $r=0.749, p<0.0001$ ) and the over the age of 7 . In addition, by separate analysis as classified by age groups, the correlation coefficient between ambulance transports due to heat stroke and mean air temperature was the highest in subjects with over 65. However, the lowest air temperature was not correlated with ambulance transports due to heat stroke. Higher air temperature was closely associated with higher ambulance transports due to heat stroke using daily data in Saitama prefecture in August, 2010, Japan, especially in elderly subjects.
\end{abstract}

Keywords: Air Temperature; Ambulance Transports; Heat Stroke; Saitama Prefecture; Japan

\section{INTRODUCTION}

Heat stroke in summer in Japan has become public health challenge in Japan. We have previously showed that positive changes in air temperature in some areas in Japan [1,2]. Higher air temperature was closely associ- ated with higher ambulance transports by monthly data in Takamatsu [3] and Okayama [4] areas, Japan. By using daily data, significant relationship between high air temperature and high ambulance transports was noted in Osaka area in August, 2009, Japan [5]. In addition, we explored, by ecological study, the link between high air temperatures and ambulance transports due to heat stroke in 47 prefectures, Japan [6]. However, the relation between high air temperature and ambulance transports by heat stroke by using daily data still remain to be investigated. In addition, separate analysis classified by age groups in the link between high air temperature and heat stroke is urgently required.

Therefore, in this study, we evaluated the link between air temperature and ambulance transports due to heat stroke using daily data, especially in elderly subjects, in Saitama prefecture in August 2010, Japan.

\section{METHODS}

Study area. Saitama prefecture is an inland prefecture situated on the northern border of Japan's capital. As large-scale industrial parks were built in former Omiya (presently Saitama City), Fukaya, Kawagoe, Sayama, and other cities, Saitama evolved from an agricultural prefecture into one whose economic activity is based on industry. Saitama's population surpassed the 7-million mark in 2002, more than 3 times the 1950 of 2.14 million [7].

Ambulance data. Daily incidence data of ambulance transports due to heat stroke in Saitama prefecture, Japan was obtained from Saitama Prefecture Official Web page from August 1 to 31, 2010 [8]. These data are consisted of number of transfers and the particular reason for heat stroke.

Meteorological parameters. Daily meteorological parameters in Saitama prefecture, Japan for the required periods were obtained from Japan Meteorological Agency [9]. The observation spots (Saitama city) were located at the central and the biggest city in the area. Daily me- 
teorological parameters i.e. mean air temperature $\left({ }^{\circ} \mathrm{C}\right)$, the highest air temperature $\left({ }^{\circ} \mathrm{C}\right)$, the lowest air temperature $\left({ }^{\circ} \mathrm{C}\right)$, and daylight hours (hours) were used for analysis.

Statistical analysis. Simple correlation analysis was used to test the significance of the linear relationship among continuous variables. In addition, $x^{2}$ test was performed: $p<0.05$ was considered to be statistically significant.

\section{RESULTS}

Clinical parameters are summarized in Table 1. A total of 1688 ambulance transports due to heat stroke was observed through August, 2010 in Saitama prefecture. Seven hundred and twenty one subjects $(42.7 \%)$ were over the age of 65 and 771 subjects $(45.7 \%)$ were aged 18 - 65 years, 189 subjects $(11.2 \%)$ were aged 7 years 18 years and 7 subjects $(0.4 \%)$ were under the age of 7 . Mean air temperature was $29.4^{\circ} \mathrm{C} \pm 1.2^{\circ} \mathrm{C}$ among obser- vation period.

We evaluated the relationship between ambulance transports due to heat stroke and air temperatures and daylight hours (Table 2). In total subjects, ambulance transports due to heat stroke was significantly correlated with mean air temperature $(r=0.749, p<0.0001)$ (Figure 1), the highest air temperature and daylight hours. However, the relationship between ambulance transports due to heat stroke and the lowest air temperature was not noted.

We further analyzed separate analysis by classified by age groups. Except under the age of 7, ambulance transports due to heat stroke were significantly correlated with mean air temperature, the highest air temperature and daylight hours. The correlation coefficient between ambulance transports due to heat stroke and mean air temperature was the highest over 65 among variables (Table 2, Figure 2). Finally, we evaluated the relationship between mean air temperature and number of persons transported per day as classified by age group using $x^{2}$

Table 1. Clinical characteristics in Saitama prefecture in August, 2010, Japan.

\begin{tabular}{|c|c|c|c|}
\hline & Mean \pm SD & minimum & maximum \\
\hline Number of days & 31 & & \\
\hline \multicolumn{4}{|l|}{ Ambulance transports due to heat stroke } \\
\hline Average number of persons transported per day & $54.5 \pm 36.9$ & 8 & 170 \\
\hline$<7$ (years old) & $0.2 \pm 0.4$ & 0 & 1 \\
\hline $7 \leq<18$ & $6.1 \pm 4.9$ & 0 & 21 \\
\hline $18 \leq<65$ & $24.9 \pm 19.5$ & 3 & 93 \\
\hline $65 \leq$ & $23.3 \pm 14.4$ & 3 & 62 \\
\hline Mean air temperature $\left({ }^{\circ} \mathrm{C}\right)$ & $29.4 \pm 1.2$ & 26.3 & 31.4 \\
\hline The highest air temperature $\left({ }^{\circ} \mathrm{C}\right)$ & $34.5 \pm 2.2$ & 29.4 & 37.9 \\
\hline The lowest air temperature $\left({ }^{\circ} \mathrm{C}\right)$ & $25.5 \pm 1.1$ & 23.6 & 27.3 \\
\hline Daylight hour (hour) & $7.4 \pm 4.0$ & 0.1 & 12.3 \\
\hline
\end{tabular}

Table 2. Simple correlation analysis between ambulans transports due to stroke and temperature in Saitama prefecture in August, 2010, Japan.

\begin{tabular}{lcccccccccc}
\hline & \multicolumn{2}{c}{ All subjects } & \multicolumn{2}{c}{$7 \leq<18$} & & $18 \leq<65$ & & $65 \leq$ \\
\cline { 2 - 9 } & $r$ & $p$ & $r$ & $p$ & $r$ & $p$ & $r$ & $p$ \\
\hline Mean air temperature $\left({ }^{\circ} \mathrm{C}\right)$ & 0.749 & $<0.0001$ & 0.636 & 0.0001 & 0.703 & $<0.0001$ & 0.746 & $<0.0001$ \\
The highest air temperature $\left({ }^{\circ} \mathrm{C}\right)$ & 0.699 & $<0.0001$ & 0.606 & 0.0003 & 0.632 & 0.0001 & 0.726 & $<0.0001$ \\
The lowest air temperature $\left({ }^{\circ} \mathrm{C}\right)$ & 0.293 & 0.1091 & 0.141 & 0.4489 & 0.308 & 0.0916 & 0.284 & 0.1222 \\
Daylight hour (hour) & 0.464 & 0.0085 & 0.491 & 0.0051 & 0.405 & 0.0239 & 0.473 & 0.0072 \\
\hline
\end{tabular}




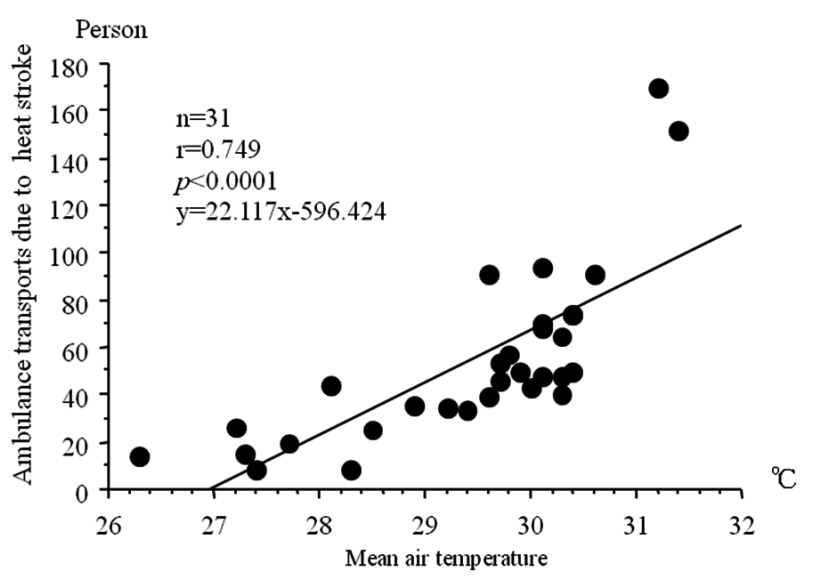

Figure 1. Simple correlation analysis between ambulance transports due to heat stroke and mean air temperature in Saitama prefecture in August, 2010, Japan (All subjects).

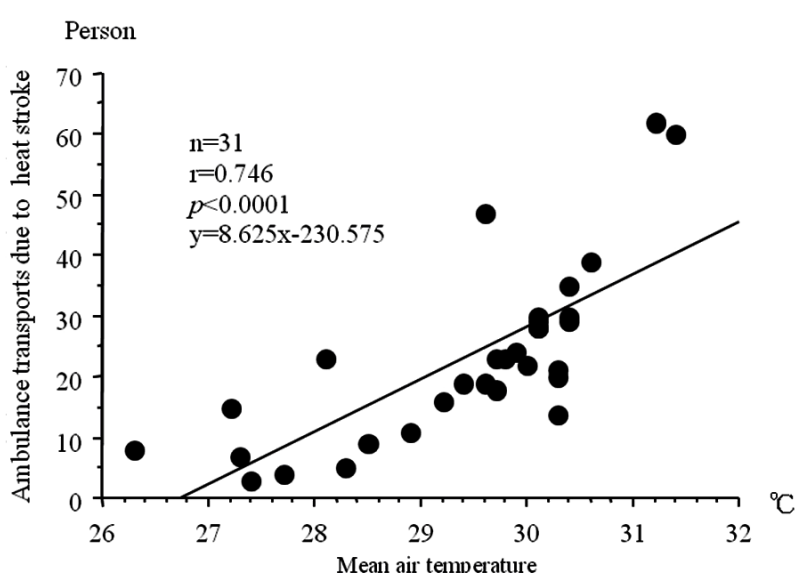

Figure 2. Simple correlation analysis between ambulance transports due to heat stroke and mean air temperature in Saitama prefecture in August, 2010, Japan (Over 65).

Table 3. Relationship between mean air temperature and number of persons transported per day as classified by age group.

\begin{tabular}{lllll}
\hline & & & & \\
& & & \\
& & & \\
& & $<65$ & $65 \leq$ & $p$ \\
Mean air temperature & $<30^{\circ} \mathrm{C}$ & 327 & 274 & 0.0759 \\
& $30^{\circ} \mathrm{C} \leq$ & 640 & 447 & \\
\hline
\end{tabular}

test (Table 3). Under $30^{\circ} \mathrm{C}$ in mean air temperature, elderly subjects over 65 was more transported due to heat stroke compare to under 65 , but not at a significant level $(p=0.0759)$.

\section{DISCUSSION}

The main finding of this study was that we explored the mean air temperature was closely associated with ambulance transports due to heat stroke using daily data in Japan, especially in elderly subjects.

By using monthly data in our previous reports $[3,4]$, mean temperature of maximum air temperatures in a month was closely associated ambulance transports in Takamatsu area $(r=0.738, p=0.0017)$ [3] and also in Okayama area, Japan $(r=0.722, p=0.0024)$ [4]. By using daily data, the highest air temperature was significantly correlated with total ambulance transports in Osaka area $(r=0.347, p=0.0007)$ [5]. We also found, by ecological study, that the correlation coefficient between mean of the highest air temperature and ambulance transports due to heat stroke in 47 prefectures in August, 2009 was the highest [6]. Our results in this study were almost similar to our previous reports and the higher air temperature was critically involved in higher ambulance transports due to heat stroke. In addition, 721 subjects $(42.7 \%)$ were over the age of 65 and the correlation coefficient between mean air temperature and ambulance transports due to heat stroke was the highest.
In addition, under $30^{\circ} \mathrm{C}$ in mean air temperature, elderly subjects over 65 was more transported due to heat stroke compare to under 65 , but not at a significant level. Taken together, unexpectedly high air temperatures may be particularly difficult for the elderly.

It is well known that the relation between higher air temperature and heat-related disease or death. Qiu et al. reported that an unusually hot spell in 1999 was followed by a high mortality rate in Hokkaido, Japan [10]. Bai et al. also showed that the number of unusual deaths in the summer of 1994 in Osaka, Japan was more compared to those of previous years [11]. Nakai et al. investigated heat-related deaths in Japan from 1968 through 1994 and heat-related deaths were most prone to occur on days with a peak daily temperature above 38 degrees $\mathrm{C}$ [12]. They reported that incidence of heat-related deaths showed and exponential dependence on the number of hot days [12]. Global average temperatures are predicted to increase between $1.4^{\circ} \mathrm{C}$ and $5.8^{\circ} \mathrm{C}$ by the end of this century [13]. Taken together, we think reasonable to suggest that simply dealing with high air temperatures in summer in Japan i.e. innovation of the thermal energy metabolism in cities and individual coping with high air temperatures might result in the amelioration of ambulance transports and heat stroke in Japan.

Potential limitations still remain in this study. First, the link between ambulance transports due to heat stroke 
and air temperatures, which was noted in this study, may not apply for the link among individuals. Second, we could not directly evaluate heat-related diseases or deaths. Further studies are required to prove such link.

\section{CONFLICT OF INTEREST}

There is no conflict of interest.

\section{ACKNOWLEDGEMENTS}

This research was supported in part by research grants from fukutake science \& culture foundation, Japan.

\section{REFERENCES}

[1] Miyatake, N., Sakano, N., Murakami, S., Suna, S., Suzue, T. and Hirao, T. (2011) Comparison of temperatures among rural, urban and metropolitan areas around the Inland Sea in Japan. Environmental Monitoring and Assessment, 181, 525-530. doi:10.1007/s10661-010-1846-0

[2] Sakano, N., Miyatake, N., Murakami, S., Suzue, T., Hirao, T. and Ogino, K. (2011) Changes in temperatures in Okayama area compared with different urbanization areas, Japan. Journal of Environmental Protection, 2, 162-167. doi:10.4236/jep.2011.22018

[3] Miyatake, N., Sakano, N., Murakami, S., Suna, S., Suzue, T. and Hirao, T. (2011) Higher temperatures were closely associated with higher ambulance transports in Takamatsu area, Japan. Journal of Environmental Protection, 2, 72-75. doi:10.4236/jep.2011.21007

[4] Sakano, N., Miyatake, N., Suzue, T., Suna, S., Hirao, T. and Ogino, K. (2011) The relation between high temperatures and ambulance transports in Okayama city, Japan (in Japanese). Journal of Preventive Medicine, 6, 17-20.

[5] Miyatake, N., Sakano, N., Murakami, S., Suzue, T., Yoda, T., Yoshioka, A. and Hirao, T. (2011) Air temperature was associated with ambulance transports in Osaka area, Japan. Health, 3, 545-548.

doi:10.4236/health.2011.39092

[6] Miyatake, N., Sakano, N. and Murakami, S. (in press) The relation between ambulance transports stratified by heat stroke and air temperatures in all 47 prefectures of Japan in August 2009, Japan: Ecological study. Environmental Health and Preventive Medicine.

[7] Saitama prefecture official website (2011). http://www.pref.saitama.lg.jp/site/english-top/english-saita ma-prefecture-at-a-glance.html

[8] Saitama prefecture official website (2011). http://www.pref.saitama.lg.jp/uploaded/attachment/45409 $\underline{0 . p d f}$

[9] Japan Meteorological Agency (2011). http://www.data.jma.go.jp/obd/stats/etrn/view/daily a1.p hp?prec no $=43 \&$ prec ch $=\% 8 \mathrm{D} \% \mathrm{E} 9 \% 8 \mathrm{~B} \% \mathrm{CA} \% 8 \mathrm{C} \% \mathrm{~A} 7$ \&block no $=0363$ \&block $\mathrm{ch}=\% 82 \% \mathrm{~B} 3 \% 82 \% \mathrm{~A} 2 \% 82 \%$ $\underline{\mathrm{BD}} \% 82 \% \mathrm{DC} \&$ year $=2010 \&$ month $=8 \&$ day $=\&$ elm $=$ daily $\&$ view $=$

[10] Qiu, D., Tanihata, T., Aoyama, H., Fujita, T., Inaba, Y. and Minowa, M. (2002) Relationship between a high mortality rate and extreme heat during the summer of 1999 in Hokkaido Prefecture, Japan. Journal of Epidemiology, 12, 254-257. doi:10.2188/jea.12.254

[11] Bai, H., Islam, M.N., Kuroki, H., Honda, K. and Wakasugi, C. (1995) Deaths due to heat waves during the summer of 1994 in Osaka Prefecture, Japan (in Japanese). Nihon Hoigaku Zasshi, 49, 265-274.

[12] Nakai, S., Itoh, T. and Morimoto, T. (1999) Deaths from heat-stroke in Japan: 1968-1994. International Journal of Biometeorology, 43, 124-127. doi:10.1007/s004840050127

[13] Intergovernmental Panel on Climate Change (2001) Climate change 2001, "The scientific basis: Contribution of working group 1 to the third assessment report". Cambridge University Press, Cambridge, 1-994. 